\section{INFANTILE PARALYSIS.}

\author{
A CIINICAL STCDY.
}

\author{
BX
}

\section{J. M. GILL, M.D.LoND.,}

FIYSICIAN TO THE SYDNEY HOSPTTAL AND TO THE ROTAL ALEXANDRA HOSPITAL FOR CHFLREN, SYDNEY, N.S.W.

There have been many epidemics of infantile paralysis in Australia and New Zealand during the present century. The first occurred in Sydney in 1903, during November and December, when about forty cases were treated at the Children's Hospital. From Sydney it spread during the course of the following year over the greater part of New South Wales and Queensland. From 1903 to 1909 there was an interval, but from 1909 to 1916 there were annual epidemics, always reaching their height in the later balf of the summer and in the autumn. There was again an interval till 1921. There were mild epidemics in Sydney in 1921,1923 , and 1924, but none this year (1925). In 1923 I collected the notes of about ten or twelve cases altogether, some being doubtful. In 1923 there were forty cases in the hospital, seventeen being under my care; one doubtful rase was fatal, but no post-mortem examination was allowed. In 1924 there were forty-five cases in the hospital, one fatal; no post-mortem examination was allowed. The last two epidemics were very similar. They both reached their maximum later than usual. In 1923 most rases were admitted in May, a cool month; in 1924 in March. Both epidemics were mild, with a high recovery and a low mortality rate. A very extensive epidemic visited New Zealand, but not Australia, in 1925.

Age.-Of forty cases in the Children's Hospital in 1923, oighteen were between 1 and 2 years of age, and twelve between 2 and 3 jears; that is, thirty out of forty were in the second and third years of life. There was only one under 12 months (7 months); the oldest was 8 years of age. The age incidence in the 1924 epidemic was very similar. These figures agree with those published by other writers. In Sydney cases in adults have been very rare, and the disease is very seldom seen even in adolescent boys and girls.

Most authors follow Wickman and describe eight clinical types. These are usually given as follows:

1. Spinal or common type.

2. Landry's paralysis type.

3. Bulbar or pontine.

4. Encephalitic type, which is responsible for many of the fatal cases in infants.

5. Neuritic type. There is some doubt about this forming a separate group, as neuritic symptoms are very common in the spinal form. Speaking for myself, I have never seen a case in which the central nervous system was not involved.

6. Meningitic form.

7. Transverse myelitis type.

8. Abortive form.

The classification into types is convenient, as the symptoms vary a good deal in different cases.

CASE 1.-Rigidity of Spine with Paralysis of Legs.

r shall begin by describing a typical case in the Children's Hospital last year (1924). She had been treated at the outdoor department for about a week before admission. She was 1 year and 10 months old, well nourished and healthy-looking. She cried as the cot was approached, and evidently found the process of undressing preparatory to examination very disagreeable. placing the hand behind her head, the neck was found to be stiff and the child cried with pain. On raising her from the bed the whole spinal column was found to be rigid, and the child fell quite helplessly back when the hand was removed. Both legs were paralysed, one more completely than the other; both kneejerks were absent. T'he paralysed muscles were all faccid and not tender on handling. The arms appeared to be perfectly not tender on handling

We have here a typical case, which would usually be explained thus:

1. The paralysis of the legs, due to the disease affecting the motor cells of the anterior cornua in the lumbar enlargement, the familiar lower motor neurone lesion.

2 . The rigidity of the neck and trunk, due to irritation of the different nerves by the pia mater, which is usually much engorged and infitrated with leucocytes-that is, Wickman's Type 6.
3. Paralysis of the neck and trunk, which rendered the child quite unable to maintain herself in the sitting posture, was due to a general involvement of the motor cells in the spinal cord.

This kind of case is the most common and ends in complete recovery except for some of the muscles of the legs.

CASE II.-Rigidity of Legs.

A child, aged $2 \frac{1}{2}$ years, had rigidity of the neck and spine, and paralysis of the muscles of the trunk, but with the legs rigid and stiff in the extended position. The knee-jerks were exaggerated. This case differs from the other, only becarase the lumbar entargement has escaped injury. It corresponds to the meningitic type of Wickman.

CASE III.-Rigidity and Flaccidity of the Legs.

A child, aged 2 years, presented a combination of the symptom of the previous two: some of the muscles of the legs were rigid, while others were flaccid. One leg was kept stiff with the kne extended, and the knee-jerk was eraggerated; the other was quite extended, and the knee-jert was exaggerated; the

This last type is quite common, although not so common as the first case. Rigidity of the legs quickly disappears, generally in a week or two, leaving the limbs more or less completely paralysed. Probably rather less than half of all cases show rigidity; though in some it may have been present before admission. Wickman called attention to this condition and recognized its cerebral origin; he suggested that it was caused by the spread of the inflammatory process from the anterior cornua to the lateral columna, thereby leading to a condition similar to lateral sclemsis. The rigidity of the trunk does not disappear so rapidly as that of the legs, and stiffness of the neck last of all. Paralysis of the trunk and neck remains long after all stiffness has disappeared-that is, the child is unable to raise itself into the sitting posture in bed and unable to maintain itself in that position even when placed in it. These three types constituted the vast majority of all cases in our last two epidemics. There were indeed some mild cases, which showed no rigidity, but yet had paralysis of the trunk. I give the notes of one such child under my own care.

A boy, aged 4 years, was admitted on April 19th, 1921, with a history, af week's illness; the onset was said to be sudden with paralysis of both legs and inability to walk. When examined on April 20 th he had fair power in the legs and no anaesthesia. April couth not sit up in bed or stand. There was no head retracHe could not sit up in bed or stand. There was no head retraction or other stiffness. The knee-jerks were absent. The legs moved freely when tested with a pin prick. On April 25th ho
could sit up; the knee-jerks were still absent. On May 2nd ho could sit up well; the knee-jerks were still absent. Three days later he could sit up quite well, but could not stand; the kneejerks were present, but difficult to get. By May 16th be was improving, and could stand with assistance. He was dischar
well, on June 2nd. The temperature was normal throughout.

In this mild case paralysis of the trunk was the most prominent symptom; the legs were only slightly affecterl and the arms not at all. Such cases, though, without rigidity are rare.

In this case, a girl aged 1 year and 10 months, the onset was quite sudden. She was quile well on March 27 th at 11 a.m. She was suddenly seized with paralysis and was admitted to hospital the following day, when it was found that she was unable to stand or sit up. The legs were fiaccid, but the knee-jerks were present. There was some difficulty in micturition and defaecation, which, however, quickly disappeared. Recovery was rapid and continuous. She was discharged on June 1st, haring made a complete recovery.

This case is of interest becruse the mother was able to state almost to a minute when the paralrsis set in. It suggested at the time that there was a vascular lesion. It is difficult to conceive a diffuse lesion of the spinal cord arising in this way. The different symptoms shown by the cases quoted will now be discussed.

\section{Rigidity of the Neck.}

Rigidity of the neck is a very common symptom in infantile paralysis; it is present in 80 per cent. of all cases, according to Foster. I have not endeavoured to work out the percentage in our cases, as many are not admitted till after all acute symptoms have subsided. It is probably entirely absent in a few only. It varies a great deal in severity from day to day and from case to case. Retraction may be so marked that the child can only lie on its sicle. In mild cases it may be necessary to flex the patient's neck 
to bring rigidity out. The muscles all round the neck, back and front, are stiff. Usually great pain is caused by any attempt to flex the neck. It may be very variable from day to day; it may even be very stiff one day and quite relaxed the next. The mistake should not be made that it is voluntary on the part of the child.

Rigidity of the nock in infantile paralysis is precisely similar to that of the common furms of meningitis in childhood, but the extreme degree of retraction sometimes sien in the pneumococcal or posterior basic form, in which the occiput may almost touch the buttock, does not occur.

It is important to realize that this symptom is not necessarily due to meningitis, although it is often the most prominent sign. In cerebro-spinal meningitis it is of c;iurse usually rery well marked, as also in the posterior basic form described by Barlow and Lees. In tuberculous meningitis it is only occasionally present, is never early, is less intense, and is much less persistent. In pneumococcal moningitis it is sometimes present and well marked. All writers remark on the frequency with which it appears in meningitis of the posterior fossa. It may also appear as the result of otitis media, disappearing as the ear gets well. But it is frequently present when there is no meningitis at all, as in pneumonia. In severe cases of gastro-enteritis it may be very marked, again without any sign of menipgitis, and of ten ends in complete recovery. In pneumonia it does not seem to add to the gravity of the prognosis, and does not usually last more than two or three days. The absence of actual pneumococcal meningitis can be established by lumbar puncture. I have seen it also in a case of cerebellar tumour. At the post-mortem examination a tumour was found in the left lobe of the cerebellum, but no meningitis. This child was aged 2 rears, and during life had been looked upon as an example of the chronic form of cerebro-spinal meningitis, owing to the marked retraction of the head and rigidity of the spine and legs. Though rare in typhoid fever, it may occur, leading to the well known clinical resemblance between this fever and meningitis. Almost any toxic condition in a small child can lead to it. For instance, a child was admitted to hospital with a retraction of the head due to a sinus in the buttock. The sinus healed after a few days' treatment, and the retraction of the head disappeared at the same time. It is therefore certain that rigidity of the neck, trunk, and legs may appear in children as the result of a great variety of infections without meningitis, and also from cerebellar tumour.

It has been suggested that retraction of the head is due $t_{1}$ increased fluid collecting in the cerebello-pontine angle. This explanation cannot apply to infantile paralysis, as the rigidity of the spine and legs must be explained also. I believe that it is generally supposed that in meningitis of the posterior fossa irritation of the first three cervical nerves, direct or reflex, leads to head retraction. This explanation is inadequate for two reasons: it does not account for the cases where there is no meningitis, and it does not take into account the effect of meningitis on the cranial nerves in the posterior fossa. If there be irritation of the cervical nerves, should there not be also irritation of the cranial norves? Spasm of any of the muscles supplied by the facial and other nerves traversing the posterior fossa is unknown in meningitis and the other conditions described gbove. The supposition that rigidity of the neck is due to "irritation" may therefore be dismissed.

Rigidity of the spine frequently accompanies retraction of the neck in infantile paralysis, though not always. When it is present it clears up before the latter. It is of ten present in meningitis. It is evidently similar in nature and origin to retraction of the neck, the same causes leading to each. It is obvious, of course, that " irritation" is an inadequate explanation, since the extensors of the trunk alone are involved in the spasm, the flexors escaping altugether, as well as the muscles of the arms, and frequently those of the legs. The abdominal muscles always escape.

The rigidity of the legs has already been mentioned. In my experience, the legs are always kept in the extended pisition. The spastic condition never lasts long, disappearing before that of the trunk. It is clearly of cerebral origin, although it is doubtful whether Wickman's sugges- tion that it is due to involvement of the lateral columns by the inflammatory process is the true one.

Any satisfactory explanation of these phenomena must apply to all three, since the same characters belong to each. In each certain muscles only are spastic-namely, those which maintain the trunk and limb in the extended position; the muscles of the upper limbs remain free, as well as the abdominal muscles. The spasm mar be maintained for days and weeks. Now these are the attributes of crintracting muscles, subserving " posture," as pointed out by Sherrington; the "lengthening and shortening" reactions are difficult to demonstrate, as the muscles are too tender as a rule to admit of much manipulation. But there is no doubt that the attitude of a child with infautile paralysis may be very similar to that of the decerebrate animal, dog or cat, described by Sherrington, with the significant exception that the arms of the child are not rigid, like the forelegs of the animal, which are used for standing. As Sherrington puts it, the position is one of reflex standing. Following Hughlings Jackson, one may attribute the rigidity to loss of cerebral control. Warner and Olmsted have lately described a tract, proceeding from the cortex of the frontal lobe, capable of inhibiting decerebrate rigidity, as postulated by Hughlings Jackson. One is naturally tempted to think that this tract may be injured in some part of its course. Decerebrate rigidity may also be inhibited by electrical stimulation of the vermis of the cerebellum, as Sherrington and others have pointed out. There is nothing in the clinical aspect of rigidity to lead one to a definite conclusion as to how inhibition may bo brought about in the human being. It is clear, however, that in infantile paralysis we sometimes have a clinical condition strictly comparable to the " decerebrate rigidity" described by Sherrington, as occurring in a cat, the section passing posterior to the mid-brain, but leaving the pons and cerebellum intact.

Retraction of the neck is not so often seen in the adult as in the child, and when present is usually less marked. Tumours and abscesses in the cerebellum, haemorrhage into the posterior fossa, and meningitis just about exhaust the list. The neck is generally rigid rather than retracted. In a boy aged 15 retraction of the neck was the most marked symptom. In the adult pneumonia is never associated with rigidity of the neck, so far as $I$ know, nor are any of the other toxic conditions already mentioned. The question arises, then, Why should retraction and rigidity of the neck occur so frequently in childhood in a variety of diseases in which it is never present in the adult? No satisfactory answer to this question has been given. The rigidity of the adult presents exactly the same attributes as that of the child; it is certain that a similar mechanism is involved in each. It is reasonable to suppose that in the child rigidity, being a more primitive (a lower level) function, is less completely inhibited than in the adult. In other words, it is a "release" phenomenon, in Hughlings Jackson's sense.

Paralysis of the Trunk.

Paralysis of the trunk usually occurs side by side with rigidity. Rigidity may be absent in exceptional cases as already mentioned. In most cases in which rigidity and paralysis of the trunk are combined rigidity clears up before the paralysis. Generally speaking, rigidity disappears in a week or two, or a month at most, while the trunk still remains paralysed. A child, aged 17 months, under treatment in 1923, admitted with paralysis of the trunk and rigidity of the neck and trunk, did not recover the power of sitting up in bed for seren and a half weeks. During the whole of this time she lay on her back in bed quite helpless, unable even to turn in bed; there was no paralysis of the legs or arms, but the knee-jerks were exaggerated. Complete recovery took place without wasting of any of the muscles.

A lesion of the lower motor neurone is not infrequently absent, but at the age at which infantile paralysis is common paralysis of the trunk is the most characteristic symptom. It is demonstrated by putting the child on its back in bed, placing the hand behind the shoulders and raising them from the horizontal to the sitting-up position. If there be rigidity, the head, neck, and trunk may be held 
in one almost straight line; but still the child is absolutely helpless. This symptom does rot, I think, occur in other diseases than infantile paralysis in early childhood. I noticed, for instance, in a case of pneumococcal meningitis, that the child was able to raise herself in bed without any special difficulty, although her neck and back were quite stiff. This child appeared to be recovering, but died soon after.

This paralysis of the trunk is too obvious a symptom to have escaped notice before. Many writers mention it, but do not attach any special importance to it, evidently looking upon it as one of the many manifestations of the lesion of the lower motor neurone. There are two sufficient reasons for rejecting this view. (1) Any subsequent wasting of the muscles of the trunk is unusual. Complete recovery is the rule, although it may take some weeks, as in the case already quoted. This is in striking contrast to the paralysis of the legs, in which complete recovery is the exception. In the last two epidemics, which have formed the principal basis of this paper, only one case of residual paralysis of the muscles of the neck or trunk was observed. This child recovered completely from the paralysis of the trunk after about two months, but paralysis of the muscles of the neck remained with wasting. A mechanical contrivance had to be devised to hold her head up. In this case it was clear that the motor cells in the upper cervical portion of the cord had been destroyed. Permanent paralysis of the muscles of the abdominal wall is also rare. (2) Usually the muscles of the upper extremity, and occasionally those of the upper limb, escape paralysis altogether. It is impossible to suppose that such a widespread and destructive lesion could involve the thoracic and cerrical portions of the spinal cord and leare out the cervical and lumbar enlargements.

There must be some connexion between this paralysis of the trunk and the rigidity previously described. They have much the same muscular distribution and are generally associated with one another. It is natural to suppose that the cerebellum is the organ involved. Usually the child can carry out all voluntary movements other than those involved in the assumption of the erect posture. The child can talk, feed itself, and otherwise use the hands as well as ever. It can move the legs in bed, lift them up, and carry out any ordinary muscular movement; but yet cannot use the legs for standing. It is clear that we have here no ordinary form of muscular paralysis, due to disease of the lower motor neurone. The incidence of the paralysis shows clearly that it must be of cerebral origin. Ir cannot be due to disease of the cerebral cortex, as all ordinary voluntary movements can be readily carried out, apart from those of the trunk. "Atonia" has been regarded as a result of disease of the cerebellum for many years. It is clear that in infantile paralysis the function of standing is lost for a time. This function is almost automatic. It is also exceedingly interesting that rigidity of the neck and trunk should be so often combined with paralysis of the trunk in infantile paralysis, and yet be dissociated from it in other cases; also that in some cases of meningitis rigidity should exist without any real paraJysis of the trunk. The explanation would seem to be that in meningitis the cortex alone is injured, while in infantile paralysis the cerebellum is injured in addition.

The question arises, Why are these two symptoms, rigidity and paralysis, so common at this early age, whether the case be one of infantile paralysis, meningitis, pneumonia, gastro-enteritis, or other form of toxaemia? I think that one of Hughlings Jackson's axioms may be the answer to this question-namely, that the most recently acquired function is the first to be lost in disease of the nervous system. The most important functions a child acquires during the first two years of life are those of standing and walking. Few things are more striking in the newborn infant than the total want of tone in the muscles of the neck and trunk. It is continually exercising the muscles of the legs and of the arms, but it has no control whatever over the muscles of the neck. It is not tiil after about three months that the child is able to hold the head up; at about 12 months of age it should be able to stand and perhaps to walk. This process is very slow and gradual; even when acquired, the child is for a long time very unstable in standing, running, or walking. It seems reasonable to suppose that this function is particularly vulnerable in the second and third years of life when infantile paralysis is common. No doubt the cerebellum is the organ which controls it. The cerebellum exercises, in conjunction with the medullary and pontine nuclei, a tonic influence on the muscles of the trunk especially, and on those of the legs to a less degree, which makes the assumption of the erect posture possible. In infantile paralysis the power of assuming the erect posture is lost altogether for a time in many cases.

Landry's Paralysis and other Types.

The acute ascending type, which is often fatal and which resembles the form of paralysis described by Landry in 1859, has not formed a feature of recent epidemics in Sydney. It usually occur's in older children, and includes most of the fatal cases in some epidemics. It seems likely that further investigation along the lines here set forth might give useful results. The cerebral type is very apt to be mistaken for meningitis; there may be rigidity of the neck with convulsions, as in one of my cases. A child, aged 1 year and 11 months, was admitted in general convulsions in March, 1909; the convulsions next day were limited to the left half of the body. The left half of the body was paralysed. She was subject to fits of the Jacksonian type for some ten years, and then she passed from my observation. The cerebral cortex was no doubt the chief seat of disease in this child. Is it too much to assume that the cerebellar cortex was also affected?

I did not intend in this paper to deal with the subject of rigidity in anything like a comprehensive way, but merely to discuss one aspect of it. The work of the late Professor Hunter has directed the attention of the profession to the whole question, in a most lucid and masterly fashion. Almost all the observations given in this papeer were carried out before his work was published. The issues of the British Medical Journal of January 31st, February 7th, 14th, 21st, and 28th, 1925, which contain references to recent rescarches bearing on the subject, should be consulted for a full description of Hunter's work.

\section{THE ACTION OF PITUITARY EXTRACT ADMINIS- TERED BY THE ALIMENTARY CANAL.}

BY

H. H. KNAUS, M.D.

ASSISTANT AT THE UNIVERSITY CLINIC FOR GYNAECOLOGY AND OBSTETRICS, GRAZ; ROCKEFELLER FELLOW. (From the Pharmacology Department, Cambridge.)

Sicce von den Velden ${ }^{1}$ first showed the specific action of pituitary extract in cases of diabetes insipidus this drug has been used very widely by clinicians, and has proved a helpful remedy, not only in diabetes insipidus, but also in surgical shock, and especially for its action on the uterus. This widespread use of pituitary extract has naturally led to administration by various methods. It has been recognized generally that pituitary, when given intravenously, subcutaneously, or intramuscularly, shows a distinct influence on all those organs on which it is known to act. The effect of pituitary after any method of injection is, however, limited to a comparatively short time, and repeated injections are required in order to keep the patient under the influence of the drug. In cases where repeated injections appeared to be undesirable, nasal, oral, and rectal administrations have been tried, but there has been no unanimity as to the results. Kennaway and Mottram, ${ }^{2}$ von den Velden, Rosenbloom, ${ }^{3}$ Rowntree, Blumgart, ${ }^{5}$ Barker and Mosenthal, ${ }^{6}$ report that they have never observed any pituitary action after administration by the mouth. Wolpe, ${ }^{7}$ Hamill, ${ }^{8}$ and Donaldson, ${ }^{9}$ on the other hand, observed a distinct action after oral administration. Abel and Gisling, ${ }^{10}$ Rowntree, and Blumgart hare produced evidence of the successful application of pituitary by the nose, and finally Rosenfeld ${ }^{11}$ may be mentioned for having observed a slight effect after rectal administration. All these observations have been made clinically on patients suffering from diabetes insipidus or from uterine haemorrhage, except Hamill's investigation, which was carried out 